\title{
CURSO DE PEDAGOGIA EM QUESTÃO: DE VOLTA PARA O PASSADO?
}

Pedagogy course in question: back to the past?

Curso de pedagogía en cuestión: ¿volver al pasado?

Leda Scheibe*

Zenilde Durli**

https://doi.org/10.38117/2675-181X.formov2021.v3i1n5.29-49.

\section{Resumo}

O artigo tem como objetivo analisar algumas implicações das atuais políticas de formação de professores sobre o curso de Pedagogia. Resultado de pesquisa documental, retoma aspectos históricos do Curso para contextualizar a proposta preliminar de reformulação das Diretrizes Curriculares Nacionais (Res. CNE n. ${ }^{\circ}$ 1/2006), em discussão no CNE. Pautada no artigo 62 da LDB/1996, a reforma pretendida é um retorno ao passado, um retrocesso com a retomada das habilitações, a cisão entre bacharelado e licenciatura, a separação da formação para a Educação Infantil e os anos iniciais do Ensino Fundamental em percursos distintos, em desacordo com a formação integrada para a infância de 0 a 10 anos, entendimento construído por processos participativos ao longo de muitas décadas. Além disso, ao pretender vincular o currículo do Curso aos objetivos, competências e conteúdo da BNCC da Educação Básica, sinaliza para o avanço da perspectiva instrumental de formação de professores.

Palavras-chave: Formação de professores; Curso de Pedagogia; Políticas de formação de professores. 


\begin{abstract}
The article aims to analyze some implications of current teacher education policies on the Pedagogy course. Result of documentary research, it resumes historical aspects of the Course to contextualize the preliminary proposal for the reformulation of the National Curriculum Guidelines (Res. CNE n.1/2006), under discussion in the CNE. Based on Article 62 of the $\mathrm{LDB} / 1996$, the intended reform is a return to the past, a setback with the resumption of qualifications, the division between bachelor's and bachelor's degrees, the separation of training for Early Childhood Education and the initial years of elementary school in different paths, in disagreement with integrated training for children from 0 to 10 years, understanding built by participatory processes over many decades. In addition, by intending to link the course curriculum to the objectives, competencies and content of the BNCC of Basic Education, it signals the advancement of the instrumental perspective of teacher training.
\end{abstract}

Keywords: Teacher training; Pedagogy course; Teacher training policies.

\title{
Resumen
}

El artículo tiene como objetivo analizar algunas implicaciones de las políticas actuales de formación docente en el curso de Pedagogía. Resultado de la investigación documental, retoma aspectos históricos del Curso para contextualizar la propuesta preliminar de reformulación de los Lineamientos Curriculares Nacionales (Res. CNE n.1/2006), en discusión en el CNE. Con base en el artículo 62 de la LDB/1996, la reforma pretendida es una vuelta al pasado, un retroceso con la reanudación de las calificaciones, la división entre licenciaturas y licenciaturas, la separación de la formación para la Educación Infantil y los primeros años de la escuela primaria en diferentes caminos, en desacuerdo con la formación integrada para niños de 0 a 10 años, entendimiento construido por procesos participativos a lo largo de muchas décadas. Además, al pretender vincular el currículo del curso con los objetivos, competencias y contenidos del BNCC de Educación Básica, señala el avance de la perspectiva instrumental de la formación docente.

Palabras clave: Formación del profesorado; Curso de pedagogía; Políticas de formación del profesorado.

\section{Introdução}

Em dezembro de 2019, ano em que o Curso de Pedagogia completava seus 80 anos de existência no Brasil, mais uma vez sua finalidade e organização é colocada em questão. Agora, pelas implicações da Resolução CNE/CP n. ${ }^{\circ}$ 2/2019), emitida pelo Conselho Nacional de Educação, que define as novas Diretrizes Curriculares Nacionais 
para a Formação Inicial de Professores para a Educação Básica e institui a Base Nacional Comum para a Formação Inicial de Professores da Educação Básica (BNC- Formação).

A Resolução n. ${ }^{\circ}$ 2/2019 sinaliza para a imediata discussão e aprovação de novas diretrizes curriculares para o Curso de Pedagogia, ao determinar no seu Art.13 a existência de três tipos de curso de licenciatura, respectivamente destinados à: Iformação de professores multidisciplinares da Educação Infantil; II - formação de professores multidisciplinares dos anos iniciais do Ensino Fundamental; e III - formação de professores dos anos finais do Ensino Fundamental e do Ensino Médio. Tal determinação derruba a histórica construção das diretrizes que organizam o atual curso de Pedagogia, cuja exigência de base docente diz respeito exatamente à formação integrada de professores para a Educação Infantil e anos iniciais do Ensino Fundamental.

No dia 10 de fevereiro de 2021 a Comissão Bicameral do CNE, designada pela Portaria CNE/CP n. ${ }^{\circ}$ 17, em 11/09/2020 (CNE/2020), apresentou, em audiência pública, a "Proposta Preliminar em Discussão" para a formulação das novas DCN para o curso de Pedagogia (DCNP). Nesta proposta, entre outras observações, consta que o novo marco normativo da formação inicial de professores (Res. n. ${ }^{\circ}$ 2/2019) requereria a revogação das DCNP de 2006 (Res. CNE n. ${ }^{\circ}$ 1/2006), "com o objetivo de cumprir o artigo 62 da LDB/1996”. De volta para o passado!

Para melhor entender o significado desse retorno, entendemos ser importante explicitar momentos significativos da trajetória do Curso de Pedagogia, os embates e forças que estiveram presentes desde a sua criação até o momento atual. Destinado inicialmente, quando da sua criação no país, ao desenvolvimento científico da formação escolar, o Curso de Pedagogia, nas oito décadas de sua existência, passou por várias determinações, acompanhando os diferentes contextos pelos quais foi se estruturando a educação no país.

Na sua atual formulação legal, que data de 2006, o Curso de Pedagogia constituise numa licenciatura destinada a formar professores para a Educação Infantil e para os anos iniciais do Ensino Fundamental. Complementarmente, este curso é também responsável por formar: i) professores para o ensino nos cursos de nível médio, na modalidade normal; ii) professores para o ensino na educação profissional, área de serviços e apoio escolar; iii) profissionais para as atividades de organização e gestão educacionais; e iv) profissionais para as atividades de produção e difusão do conhecimento científico e tecnológico no campo da educação (BRASIL, 2006). Tal estruturação foi amplamente discutida pelos educadores do país durante muitos anos, até chegar à sua formulação e aprovação pelo CNE, tendo sido posteriormente referendada 
pelas DCN de formação dos profissionais da educação sancionadas pela Resolução CNE/CP n. ${ }^{\circ}$ 2/2015 (BRASIL 2015).

As determinações das novas diretrizes (Res. n. ${ }^{\circ}$ 2/2019), no entanto, pretenderiam, como evidenciamos em recente artigo, (BAZZO E SCHEIBE, 2020), uma "volta para o futuro" nas políticas de formação docente no país, tendo como base para a reforma educacional em andamento, a BNCC - Base Nacional Comum Curricular (BRASIL, 2017). Fica manifesta a intenção governamental de formar professores conformados para a consolidação do neoliberalismo como lógica dominante do capitalismo global. A BNCC da EB, instrumento central para a concepção de educação projetada pelo governo golpista, atendeu aos ditames de uma agenda global sob a batuta dos órgãos multilaterais comprometidos com a ideologia do neoliberalismo, "esta versão do capitalismo que sujeita todas as áreas sociais, sobretudo a saúde, educação e segurança social, ao modelo de negócio do capital, ou seja, às áreas de investimento privado", portanto, ao mercado. (SANTOS, 2020).

É importante salientar esta relação entre políticas globais e as políticas curriculares nacionais. A agenda global das instituições multilaterais prescreve, para o pretendido processo de globalização, uma padronização educacional, por meio de um currículo aprovado nacionalmente, (mas que de nacional tem muito pouco...) para estabelecer os padrões de qualidade a serem medidos a partir de avaliações nacionais e internacionais, com metas e padrões de aprendizagem "objetivos e mensuráveis". A qualidade docente coloca-se, portanto, segundo os padrões globais, voltada ao atendimento desses objetivos.

\section{$O$ contexto no qual se deu a universitarização da educação no país}

A sociedade brasileira vivenciou, na década de 1930, profundas mudanças econômicas, sociais e políticas, vinculadas ao que vinha ocorrendo em outras partes do mundo. Naquele período, segundo Miceli (2001), o país passava por um processo de modernização no qual é possível destacar a definição de diretrizes políticas para diversos campos da organização nacional, também para a educação, a favor dos segmentos urbanos emergentes no processo de industrialização que então ocorria.

Também Coutinho (1999), destaca que a existência aqui de uma burguesia industrial, embora ainda fraca e dependente do capital agrário-exportador e de uma sociedade civil pouco organizada, favorecia o aparelhamento do Estado, mesmo que por 
um viés autoritário e corporativo, atuando como representante político das classes economicamente dominantes.

As políticas públicas respondiam já então a uma dupla determinação: às necessidades de valorização do capital e à construção de consenso popular mínimo, necessário à estruturação de um capitalismo dependente. Em busca da concretização de tais objetivos, o Estado corporativo deveria passar a regular as relações de trabalho e a estabelecer políticas para a previdência, saúde pública e educação (SILVA, 2004).

Tal processo exigia um aparato burocrático até então inexistente, porém necessário à centralização que se estabelecia em torno da Presidência da República: criação de ministérios, uma rede de autarquias, conselhos, departamentos e comissões especiais. Neste contexto, foi criado, entre outros, já em 1930, o Ministério da Educação e Saúde Pública ${ }^{1}$, e pouco depois, após a Revolução Constitucionalista de 1932, uma nova Constituição (1934), em substituição à de 1891. Destaca-se que a nova legislação previa um Plano Nacional de Educação e a gratuidade e obrigatoriedade do ensino escolar, fatores certamente substanciais para o desenvolvimento da educação no país.

É importante referir que, ao lado da crescente urbanização no país, outras exigências de setores ligados ao campo do capital passavam a demandar mão-de-obra qualificada, comprometendo o Estado com a expansão da escolarização. Para dar conta da estrutura agora demandada, em todas as áreas de atuação estatal, tornava-se necessária a abertura de cargos especializados a serem ocupados pelos detentores de competências estritas em determinadas áreas do conhecimento, consolidando-se assim carreiras técnicas específicas e novos postos de trabalho. Conforme destaca Silva (2004, p. 31), as novas exigências

[...] passaram a reivindicar do Estado, ações educacionais que garantissem a formação de funcionários adaptados às novas funções de gerência e a tarefas especializadas, bem como para a formação de seus intelectuais orgânicos. Além disso, segmentos da sociedade civil também reivindicaram a expansão das oportunidades educacionais. Por exemplo, desde o início do século XX o operariado defendia a redução da jornada de trabalho para, dentre outras, possibilitar o acesso da classe trabalhadora à educação e às classes médias como forma de ascensão social.

As diretrizes políticas nacionais para a educação escolar foram, progressivamente, definidas e implantadas por meio de marcos regulatórios construídos pelo recém criado

\footnotetext{
${ }^{1}$ Francisco Campos assumiu a direção do recém-criado Ministério da Educação e Saúde Pública, credenciado por sua atuação à frente dos assuntos educacionais de Minas Gerais. Promoveu, então, a reforma do ensino secundário e universitário no país. Deixou o ministério em setembro de 1932.
} 
Ministério da Educação e Saúde Pública, e pelo Conselho Nacional de Educação, instalado em $1931^{2}$, durante a Reforma Francisco Campos. Ainda segundo Silva (2004, p.31), a educação, neste contexto, afirmava-se "como um serviço público e um importante instrumento para a construção de uma nova hegemonia", e as ações do Estado expressavam, de alguma forma, estratégias para a obtenção do consenso necessário à criação de condições de adaptação às relações de produção impostas pelo desenvolvimento das forças sociais em ascensão.

Assim, por ocasião da reforma proposta pelo Ministro Francisco Campos, em 1931, finalmente se instituiu no país o sistema universitário, por meio do Decreto n. ${ }^{\circ}$ 19.851/31, acompanhado do Estatuto das Universidades Brasileiras (BRASIL, 1931). Até então, existiam cursos superiores para a formação de profissionais destinados às tradicionais carreiras, tais como medicina, direito e engenharias, na forma de faculdades independentes de um sistema universitário. A profissionalização vinculada à área da educação não ocupava ainda espaço nos estudos superiores.

Segundo Saviani (2009), de 1827 até 1890, por meio da Lei das Escolas de Primeiras Letras, obrigava-se os professores a se instruírem no método do ensino mútuo, por sua própria conta. A partir de então, passa a prevalecer o modelo das Escolas Normais, em cursos de nível secundário para a formação do quadro de professores destinados aos anos iniciais de escolarização. Até 1931, contudo, ainda não havia exigência de formação profissional para aqueles professores que atuavam no nível secundário, ela passou a ser exigida após a Reforma Francisco Campos, responsável por conferir a este ensino uma organicidade legislativa considerada necessária para sua adequação à modernização nacional então em andamento (DALLABRIDA, 2009).

Com esta reforma, passou-se a requerer complementação pedagógica para o exercício do magistério no nível secundário, oferecida, inicialmente, pelos Institutos de Educação. A absorção destes institutos pelas universidades marcou o início da universitarização da formação de professores e do campo educacional no país (SAVIANI, 2009).

\footnotetext{
2 Os conselhos de educação têm sua existência, no Brasil, datada do início do período republicano, quando foram criados com o objetivo declarado de discutir e definir as políticas para a educação. O primeiro deles denominou-se Conselho Superior de Educação e foi constituído em 1891. O segundo foi organizado pela Reforma Francisco Campos, em 1931, com funções consultivas e denominava-se Conselho Nacional de Educação (CNE). Em 1961, com o advento da Lei 4.024 (BRASIL, 1961), criou-se o Conselho Federal de Educação (CFE), extinto em 1994, no governo Itamar Franco. Em 1995, pela Medida Provisória no 1.159/1995, foi recriado o Conselho Nacional de Educação (CNE), em atividade até os dias atuais.
} 
Vejamos como se deu esta absorção. Com a institucionalização universitária no país pelo Decreto n. ${ }^{\circ} 19.851 / 31$, foi inicialmente proposta a incorporação do campo do conhecimento da educação nos estudos superiores, por meio de uma Faculdade de Educação, Ciências e Letras. Essa faculdade poderia constituir uma das necessárias à criação de universidades. As outras colocadas como imprescindíveis foram as tradicionais faculdades de medicina, direito e engenharia. Tal possibilidade, ainda segundo Saviani (2019), de colocar a educação com peso equivalente a outras faculdades tradicionais, foi significativa para o reconhecimento da educação como digna de ser contemplada nos estudos superiores.

Apesar desta proposição, e de duas tentativas de sua concretização, a Faculdade de Educação, Ciências e Letras não foi efetivamente implantada, e sim, substituída pela Faculdade de Filosofia, Ciências e Letras $^{3}$, que incorporou, como veremos a seguir, a formação dos profissionais para a educação.

As Faculdades de Educação só passaram a integrar efetivamente o sistema universitário com a entrada em vigor da Lei 5.540 de 28 de novembro de 1968, regulamentada pelo Decreto-Lei n. 464 de 11 de fevereiro de 1969, durante a ditadura militar. Assim, a formação universitarizada de professores encontrou seu espaço inicial nas Faculdades de Filosofia, Ciências e Letras, porém restrita à formação para atuar no ensino secundário.

\section{Os Cursos de Pedagogia, da criação até a LDB 1996}

O Curso de Pedagogia foi instituído pelo Decreto-Lei n. ${ }^{\circ} 1.190$, de 04 de abril de 1939 (BRASIL, 1939), que deu organização à Faculdade Nacional de Filosofia, no âmbito da Reforma Francisco Campos, durante a vigência do Estado Novo. Entre suas finalidades, o Decreto previa "preparar candidatos ao magistério do ensino secundário e normal" (Art. $1^{\circ}$ do Decreto).

A Faculdade Nacional de Filosofia, então instalada, compreendia além de quatro seções fundamentais: filosofia, ciências, letras e pedagogia, uma secção especial de didática. As quatro primeiras abrigavam os cursos ordinários, e forneciam o diploma de

\footnotetext{
${ }^{3}$ Uma, implantada no Instituto de Educação da Universidade de São Paulo- IEUSP, criado e coordenado por Fernando de Azevedo em 1934; a outra, na Escola de Educação da Universidade do Distrito Federal, no Rio de Janeiro, criada e coordenada por Anísio Teixeira, em 1935 (EVANGELISTA, 2002; SILVA, 2004)
} 
bacharel: seção de filosofia o curso ordinário de Filosofia; seção de ciências os cursos ordinários de matemática, de física, de química, de história natural, geografia, história e de ciências sociais; seção de letras os cursos ordinários de letras clássicas, letras neolatinas e letras anglo-germânicas; seção de pedagogia o curso ordinário de pedagogia. Já a seção especial de didática ofertava a licenciatura aos bacharéis que desejassem seguir a profissão docente no ensino secundário.

Esse mesmo decreto tornou obrigatório, a partir de 1943, o diploma de licenciado em Pedagogia para o exercício do magistério em cursos de formação de professores (Cursos Normais) do então denominado $1^{\circ}$ grau, correspondente aos primeiros nove anos de escolarização, e o diploma de bacharel em Pedagogia para o exercício dos cargos técnicos em educação. Assim, o curso de Pedagogia nasceu com duas finalidades centrais: 1) formar técnicos em educação para atuar junto à estrutura burocrática dos sistemas de ensino, a partir da titulação de bacharel alcançada após três anos de estudos; 2) formar professores para o exercício da docência no ensino secundário, no Curso Normal, mediante o acréscimo de mais um ano de estudo, na secção especial de Didática (SCHEIBE, AGUIAR, 1999; SCHEIBE, DURLI, 2011).

Com o Decreto-Lei n. ${ }^{\circ}$ 1.190/1939, deu-se o início da universitarização da formação de professores no país. Essa formação caracterizou-se pela separação entre bacharelado e licenciatura, o conhecido "esquema $3+1$ ", no qual o bacharelado (três anos) era pré-requisito à obtenção do diploma de licenciado (+ um ano). Esta configuração curricular permaneceu no curso de Pedagogia até o final da década de 1960, embora tenha havido algumas propostas de mudança durante este período ${ }^{4}$ (SCHEIBE, DURLI, 2011).

O campo de atuação do Pedagogo como técnico em educação ainda era bastante restrito, pois as instâncias administrativas ligadas à educação, nas quais o bacharel poderia atuar, estavam em processo de organização no cenário nacional. Em relação aos pedagogos formados para atuar no magistério normal, como licenciados, disputavam esse espaço com os licenciados de outros cursos ofertados nas Faculdades de Filosofia, Ciências e Letras. Tal condição de empregabilidade dos egressos, provocada pela

\footnotetext{
${ }^{4}$ As propostas de mudança então havidas podem ser observadas nos seguintes documentos: Decreto-Lei n. 9.092, em que se tentou substituir o esquema $3+1$ pela obrigatoriedade de 4 anos de formação em faculdades de Filosofia, tanto para o bacharelado quanto para a licenciatura em Pedagogia; Parecer CFE n. 251/1962, o qual indicava as disciplinas que deveriam compor o currículo mínimo do Curso de Pedagogia; Parecer CFE n. 292/1962, que fixou as matérias pedagógicas para a licenciatura; Parecer CFE n. 12/1967, que tratou da formação de professores para as disciplinas específicas do ensino médio técnico.
} 
pequena demanda social, em um sistema de ensino que ainda se organizava, limitou a expansão do curso nos primeiros tempos de sua criação.

A ditadura militar (1964 -1985) implantou uma profunda reforma de ensino no Brasil, uma vez que o regime instaurado não poderia prescindir de consenso e de legitimação. Em razão disso, as políticas educacionais sofreram ampla reformulação: as relativas ao ensino superior em 1968, do ensino primário e médio em 1971. De acordo com Saviani (2004), os princípios de racionalidade, eficiência e produtividade, já então advogados pelo regime militar, reordenaram o processo educativo no país, de maneira a torná-lo “objetivo e operacional”, radicalizando-se uma perspectiva técnico-instrumental na reforma realizada - panorama que voltamos a verificar nas reformas hoje em andamento. Segundo o autor, a predominância do tecnicismo pedagógico e a crença no conhecimento técnico-organizacional foram responsáveis, naquela ocasião, por introduzir a divisão do trabalho na escola.

Pelo Parecer CFE n. ${ }^{\circ}$ 252/1969 e a Resolução CFE n. ${ }^{\circ}$ 2/1969, o Curso de Pedagogia passou a atender às exigências, então demandadas, do desenvolvimento das forças produtivas, com a possibilidade de opção pela trajetória curricular de acordo com as tarefas a serem desempenhadas pelo pedagogo como profissional da educação. Permaneceu então um currículo mínimo, contemplando uma parte comum do curso, e criou-se uma parte diversificada, contemplando diversas habilitações requeridas pela divisão do trabalho então estabelecida para as escolas: 1) Magistério do Ensino Normal; 2) Orientação Educacional; 3) Administração Escolar: a) Administração de Escola de $1^{\circ}$ e $2^{\circ}$ Graus, b) Administração de Escola de $1^{\circ}$ Grau; 4) Supervisão de Ensino: a) Supervisão de Escola de $1^{\circ}$ e $2^{\circ}$ Graus, b) Supervisão de Escola de $1^{\circ}$ Grau; 5) Inspeção Escolar: a) Inspeção de Escola de $1^{\circ}$ e $2^{\circ}$ Graus, b) Inspeção de Escola de $1^{\circ}$ Grau. No que diz respeito à duração do curso, fixaram-se duas modalidades: a licenciatura plena, com duração de 2.200 horas, e a licenciatura de curta duração, com 1.100 horas, destinada a formar os especialistas para atuar apenas nas escolas de primeiro grau (DURLI, 2007; SCHEIBE, DURLI, 2011).

Essa normatização, que permaneceu regulando os cursos de Pedagogia até a homologação da nova Lei de Diretrizes e Base da Educação - LDB - Lei n. o 9.394/1996, permitia três possibilidades de atuação aos egressos do curso. Duas delas, bem definidas nas habilitações então criadas - a de professor nas disciplinas pedagógicas nos cursos de formação de professores; e a de especialista, conforme a habilitação escolhida. A terceira, como uma decorrência da habilitação Magistério do Ensino Normal, a de professor primário, desde que fossem incluídos no seu percurso de formação alguns estudos mínimos, que compreendiam as cadeiras de Estrutura e Funcionamento do Ensino de $1^{\circ}$ 
Grau, Metodologia do Ensino de $1^{\circ}$ Grau e Prática de Ensino na Escola de $1^{\circ}$ Grau (estágio).

Marcada pela divisão do trabalho, essa organização ampliou o campo de atuação do pedagogo e inspirou a oferta do curso em muitas instituições no país esta ampliação da oferta também gerou preocupação por diversas razões, entre as quais as inúmeras especializações ofertadas e a consequente dispersão em relação a uma formação básica consistente para atuação autônoma e crítica quanto às suas condições de ensino e trabalho. (BRZEZINSKI, 1996; DURLI, 2007).

No final dos anos de 1970 e durante toda a década de 1980, o Movimento pela Reformulação dos Cursos de Formação do Educador, ${ }^{5}$ - movimento que deu origem à Associação Nacional pela Formação dos Profissionais da Educação - ANFOPE, em 1990 - esteve à frente de mobilizações pela exigência de efetiva formação dos profissionais da educação em nível superior, entre outras lutas referentes às condições de trabalho e carreira. Essa mobilização fortaleceu o Curso de Pedagogia enquanto lócus de formação dos professores para o então denominado Pré-Escolar e para o Ensino Primário. Esse movimento, pautado na abertura propiciada pela legislação de 1969 (Parecer do CFE n. 252/1969, e pela Resolução CFE n. 2/1969), fortaleceu na década de 80 as iniciativas institucionais de reformulação curricular dos cursos de Pedagogia nas universidades e faculdades para formar professores na especificidade dos primeiros anos de escolarização.

Para além das habilitações referentes à formação de especialistas e à docência no segundo grau, nas décadas de 1980 e 1990, outras habilitações foram autorizadas pelo Conselho Federal de Educação, voltadas à formação de professores, tais como: educação infantil, ensino primário, educação de jovens e adultos, educação especial, educação hospitalar, tecnologia ou informática na educação. Essa mudança na base da identidade formativa - de bacharelado (formação de especialistas) para licenciatura (formação de professores) -, ao mesmo tempo em que ampliava as possibilidades de atuação do pedagogo, impulsionou mais uma vez a expansão do curso.

\footnotetext{
${ }^{5}$ O Movimento pela Reformulação dos Cursos de Formação do Educador teve seu início no âmbito do Comitê Pró-Formação do Educador, nos anos de 1980 a 1983. Em 1983, o Comitê foi transformado em Comissão Nacional pela Reformulação dos Cursos de Formação do Educador - CONARCFE - e, em 1990, em Associação Nacional pela Formação dos Profissionais da Educação - ANFOPE (Durli, 2007).
} 
A legislação de 1969 permaneceu vigente até a aprovação da LDB 9.394/1996. Nesse período, houve expressiva expansão no número da oferta do curso de Pedagogia, que passou de 138 cursos no início dos anos 1970 para 513 no ano de 1996.

\section{A LDB de 1996: propostas e embate}

Controvérsias históricas sobre a formação no Curso de Pedagogia precederam a aprovação do texto da nova LDB, em 1996. A nova Lei criou os Institutos Superiores de Educação - ISEs, no artigo 63, nos quais seriam ofertados: (i) os cursos formadores de profissionais para a Educação Básica (licenciaturas ), assim como o Curso Normal Superior para a formação de docentes destinados à Educação Infantil e Séries Iniciais do Ensino Fundamental; (ii) programas de formação pedagógica para portadores de diplomas de ensino superior que quisessem se dedicar à educação básica; (iii) programas de educação continuada para os profissionais de educação dos diversos níveis.

Claramente estava posta a intenção de desuniversitarizar a formação dos profissionais da educação básica. Os ISEs foram previstos como unidades independentes, embora a Lei não impedisse, de imediato, que eles estivessem abrigados também nas universidades. Tratava-se, pois, da abertura de uma nova institucionalização, fora delas. Já o curso de Pedagogia, esvaziado do seu papel formador de professores, poderia permanecer nas faculdades ou departamentos de educação das universidades como um bacharelado para formação de especialistas.

Muito contestada pelos movimentos organizados dos educadores em favor dos cursos de Pedagogia, a LDB/1996 passou a ser regulamentada. Assim, com o DecretoLei n. ${ }^{\circ}$ 3.276, de 06 de dezembro de 1999 (BRASIL, 1999), e posteriormente com o Decreto n. ${ }^{\circ}$ 3.554, de 07 de agosto de 2000 (BRASIL,2000), o Ministério da Educação regulamentou efetivamente esta formação nos Cursos Normais Superiores dos professores para atuar na educação básica, utilizando, no entanto, o termo "preferencialmente", frente à resistência dos educadores inconformados com a retirada da formação destes professores dos cursos de Pedagogia. Entidades científicas da área da educação, particularmente a ANFOPE, ANPED e o FORUMDIR, mobilizaram forte resistência no interior das universidades e conseguiram reverter a exclusividade formativa no curso Normal Superior assim como a criação, fora das universidades, dos Institutos de Educação como locais precípuos para abrigar todas as licenciaturas.

Um número expressivo de cursos "Normal Superior" foi criado, principalmente em faculdades isoladas, em substituição ao de Pedagogia. Tal situação perdurou até a 
aprovação das novas Diretrizes Curriculares Nacionais para o curso de Pedagogia (DCNP), em 2006.

\section{As Diretrizes Curriculares Nacionais para o Curso de Pedagogia (DCNP) pós LDB: elementos de uma identidade em construção}

As Diretrizes Curriculares Nacionais para o curso de graduação em Pedagogia foram aprovadas 10 anos após a LDB, pela Resolução CNE/CP n. ${ }^{\circ} 1$ de 15 de maio de 2006 (BRASIL, 2006). Constituíram-se como resultado de longo processo coletivo de trabalho, de tensionamento entre propostas antagônicas e busca pelos consensos então possíveis em relação à identidade do Curso. Envolveu comissões internas do Ministério da Educação, Comissões Bicamerais do Conselho Nacional de Educação, Comissões de Especialistas de Ensino de Pedagogia, entidades científicas e associações da área da educação (ANFOPE, ANPEd, FORUMDIR, CEDES, entre outras) em um movimento arbitrado pelo Estado. Muitos intelectuais participaram das discussões como mediadores dos diferentes interesses presentes na arena de confronto em que se constituiu o Conselho Nacional de Educação (DURLI, BAZZO, 2008), no período de 1997 a 2006. Para compreender o alcance dos embates cabe lembrar que a aprovação da LDB de 1996 foi posicionada de acordo com o grupo que defendia os Institutos Superiores de Educação, assim como a formação dos docentes para anos iniciais e educação infantil em Cursos Normais Superiores, posição contrária àquela do Movimento dos professores e das entidades.

As discussões sobre a docência como base da formação do pedagogo foi, sem dúvida, a questão mais polemizada no longo processo que culminou com a aprovação das DCNP. Na posição de Scheibe e Bazzo (2001) a definição de uma base nacional comum à formação de todos os profissionais da educação brasileira deveria incidir também sobre a definição do Curso de Pedagogia.

A expressão "base comum nacional"6 foi cunhada pelo Movimento Nacional de Formação do Educador ${ }^{7}$, no início da década de 1980, num momento em que as forças

\footnotetext{
${ }^{6}$ A ideia de Base Nacional Comum, cunhada pelo Movimento Nacional de Formação do Educador no início dos anos 80, referia-se à necessidade de estabelecer bases comuns nacionais para todas as etapas e modalidades da educação.

${ }^{7}$ Essa mobilização iniciou-se já nos anos finais de 1970, no contexto das lutas contra o regime militar. Após 1990, a ANFOPE - Associação Nacional pela Formação dos Profissionais da Educação e, mais ou menos concomitantemente, o FORUMDIR - Fórum dos Diretores das Faculdades de Educação das Universidades Públicas Brasileiras - destacaram-se pelo acompanhamento que deram e continuam dando à
} 
sociais estavam empenhadas na redemocratização do país. A concepção de base comum nacional para a formação de professores esteve marcada, no contexto desse movimento mais amplo, por dois sentidos complementares: (i) um sentido político, caracterizando-a como instrumento de luta pela formação e pela profissionalização de todo educador; e (ii)) um sentido teórico, constituindo-a como princípio orientador dos currículos dos cursos de formação dos educadores (ANFOPE, 1998; DURLI, 2007).

No contexto desse movimento, instituiu-se como princípio basilar " $a$ docência como a base da identidade profissional de todo educador" (ANFOPE, 1998). Esse princípio passou a mobilizar intensos debates no sentido de sua formulação e, igualmente, dos seus desdobramentos sobre os cursos de licenciatura e especialmente sobre o Curso de Pedagogia (SCHEIBE E AGUIAR, 1999). As novas diretrizes, aprovadas em 2006, expressam as tensões dessas discussões ao mesmo tempo em que acolhem alguns entendimentos construídos ao longo dos anos 1980.

Entre as principais mudanças estabelecidas pelas novas diretrizes, destacam-se a alteração da finalidade do curso, a extinção das habilitações, o aumento da carga horária mínima para a sua integralização e a flexibilização curricular. Na letra da Resolução CNE/CP n. ${ }^{\circ} 1 / 2006$, o Curso se destina à:

[...] formação de professores para exercer funções de magistério na Educação Infantil e nos anos iniciais do Ensino Fundamental, nos cursos de Ensino Médio, na modalidade Normal, de Educação Profissional na área de serviços e apoio escolar e em outras áreas nas quais sejam previstos conhecimentos pedagógicos.

Parágrafo único: As atividades docentes também compreendem participação na organização e gestão de sistemas e instituições de ensino, englobando:

I - planejamento, execução, coordenação, acompanhamento e avaliação de tarefas próprias do setor da Educação;

II - planejamento, execução, coordenação, acompanhamento e avaliação de projetos e experiências educativas não-escolares;

III - produção e difusão do conhecimento científico-tecnológico do campo educacional, em contextos escolares e não-escolares. (BRASIL, 2006).

Conforme já explicitado, desde a legislação de 1969 o Curso de Pedagogia apresentava uma organização curricular configurada em "habilitações", com duas finalidades distintas: as destinadas à formação de docentes caracterizavam-se como

construção coletiva de uma base comum nacional para a formação dos profissionais da educação e pelo seu empenho na luta política para assegurar os princípios que orientam esta formação. 
licenciaturas; as dedicadas à formação de profissionais denominados especialistas em assuntos educacionais caracterizavam-se como bacharelados. Tal organização curricular, com posicionamentos contrários e favoráveis à sua manutenção, entrou em regime de extinção e o curso passou a caracterizar-se como uma licenciatura. Como expressão desse tensionamento, contudo, no texto das DCNP, ao mesmo tempo em que as habilitações são extintas, são também, de alguma forma, reafirmadas. Vejamos: “A Licenciatura em Pedagogia, nos termos dos Pareceres CNE/CP n. ${ }^{\circ}$ 5/2005 e n. ${ }^{\circ}$ 3/2006 e desta Resolução, assegura a formação de profissionais da educação prevista no art. 64, em conformidade com o inciso VIII do art. $3^{\circ}$ da Lei n. ${ }^{\circ}$ 9.394/96" (Resolução n. ${ }^{\circ} 1$, de 15 de maio de 2006). $\mathrm{O}$ artigo da LDB citado trata exatamente da formação dos especialistas ao afirmar: "A formação de profissionais de educação para administração, planejamento, inspeção, supervisão e orientação educacional para a educação básica, será feita em cursos de graduação em pedagogia ou em nível de pós-graduação, a critério da instituição de ensino [...]". Essa e outras ambiguidades presentes nas DCNP resultaram da presença de perspectivas e interesses diversos, antagônicos até, e em disputa, no processo de construção dos consensos que culminou com a homologação da Resolução CNE/CP n. $1 / 2006$.

De fato, a base docente foi afirmada no Art. $2^{\circ}$ das DCNP. Também no Art. $7^{\circ}$, o inciso II especifica que os estágios supervisionados serão realizados, prioritariamente, na Educação Infantil e nos anos iniciais do Ensino Fundamental. Ao lado da prioridade em relação à base docente do curso, a DCNP faz referência aos conteúdos de gestão e pesquisa, indicando claramente que estes conteúdos e as funções que propiciam - de gestor e de pesquisador educacionais -, devam ser acrescidas à docência.

Outra questão importante diz respeito à duração do Curso. Durante a década de 1990 as políticas de formação inicial e continuada de professores acenavam com perspectivas de aligeiramento e baixos investimentos. Em contrapartida, os sujeitos coletivos da sociedade civil já referidos, pugnaram por garantir um currículo com carga horária ampliada ao adensamento da formação, distribuída em um tempo mínimo de, pelos menos, quatro anos. A Resolução estabeleceu 3.200 horas de efetivo trabalho acadêmico, avançando em 400 horas em relação ao mínimo estabelecido pelas Diretrizes Curriculares Nacionais para a formação de Professores da Educação Básica - Resolução CNE/CP n. ${ }^{\circ}$ 1, de 18 de fevereiro de 2002 (BRASIL, 2002) - que então normatizavam a formação de professores no país, e definiam como carga horária mínima 2.800 horas. A duração de quatro anos, no entanto, não obteve êxito diante da força das políticas de aligeiramento, muito bem acolhidas por setores das IES privadas no país. Além dessa 
questão, também os indicativos de organização curricular por competências permaneceram, posta estarem bem alinhados ao já proposto na LDB.

As DCNP foram reforçadas, conservando as suas especificidades, com a definição de novas diretrizes curriculares para a formação de professores sancionadas pelo CNE em 2015 (Res. n. ${ }^{\circ} 02$ de 2015), após ampla consulta realizada junto aos coletivos de educadores.

\section{A Volta para o Passado: Implicações da Resolução CNE 02/2019 para o Curso de Pedagogia}

A Resolução CNE/CP n. ${ }^{\circ}$ 2/2015, das Diretrizes Curriculares Nacionais para a Formação Inicial e Continuada em Nível Superior de Professores para a Educação Básica, que fora amplamente discutida no percurso da sua construção, e se constituiu numa síntese das lutas históricas da área em torno do tema (BAZZO, SCHEIBE, 2020), estava em seu processo de implantação pelas IES quando o Golpe que derrubou o Governo Dilma Rousseff instaurou, em 2016, o Governo Temer; este, em seu processo de desconstrução das medidas democraticamente estabelecidas pelos dois governos anteriores, passou a atacar diretamente, também, as conquistas no campo da Educação.

Para os novos dirigentes do MEC (de trágica memória!), a formação docente transformou-se em um dos alvos destinados à instrumentalização da Educação Básica no País de acordo com o projeto governamental, tal como ocorreu após o golpe militar de 1964.

Inicialmente, já em 2017, ainda no governo Temer, foi finalizada e sancionada a Base Nacional Comum Curricular da Educação Básica - BNCC (BRASIL 2017), em grande parte determinada pela agenda global. A concepção de formação por competências que a caracteriza, segundo Albino e Ferreira da Silva (2019) configura-se como resposta à demanda do capitalismo mundial e não por uma necessidade de pensar a formação humana integral. A BNCC passou a ser o carro-chefe das contrarreformas educacionais desenvolvidas pelo MEC, como instrumento central para a imposição das mudanças no setor das políticas da escolarização básica e, consequentemente, para a formação dos seus professores e professoras.

Iniciou-se então, no MEC, a corrida para trazer à pauta do CNE a proposta de uma resolução para inviabilizar a Resolução CNE/CP n. ${ }^{\circ}$ 2/2015. O seu encaminhamento ao Conselho deu-se ainda pelo então ministro da Educação - Rossieli Soares, em dezembro 
de 2018, por meio do documento denominado Proposta para Base Nacional Comum da Formação de Professores da Educação Básica. Este texto encontra-se anexo à Res. 02/2019 que encaminha as novas DCNFP sob a denominação de Base Nacional Comum para a Formação Inicial de Professores da Educação Básica (BNC-Formação). Apresenta as pretensas competências profissionais docentes, com base em três dimensões: conhecimento profissional, prática profissional e engajamento profissional. Dez competências gerais docentes, mais as três dimensões, denominadas de competências específicas, vinham acompanhadas das inúmeras habilidades correspondentes (RAMOS, 2019).

Ao longo do ano de 2019 as novas diretrizes para a formação foram sendo elaboradas por um CNE, que após o Golpe de 2016 foi reestruturado conforme o projeto da nova ordem. Apesar da pronta reação de grande parte da comunidade educacional contra a proposta que se formulava de proscrever a Resolução CNE/CP n. ${ }^{\circ}$ 02/2015, o Conselho Nacional de Educação manteve essa política de atraso, complementando-a com a Res. CNE/CP n. ${ }^{\circ}$ 1, de outubro de 2020, que dispõe sobre as Diretrizes Curriculares Nacionais para a Formação Continuada de Professores da Educação Básica - DCNFCP (BRASIL 2020).

Com a mesma orientação, está em discussão agora no CNE a proposta de alteração das DCN de 2006, que normatizam atualmente os cursos de Pedagogia, visando especialmente uma nova formatação dos professores da educação infantil e dos anos iniciais do ensino fundamental, conforme determinação constante na Res. 02/2019, e já sinalizada na introdução deste artigo.

Segundo Freitas (2021), há claras evidências de um processo de destruição das Faculdades de Educação, que são responsáveis pelo desenvolvimento da investigação no campo da educação e da pedagogia e pela formação dos quadros do magistério no interior das Instituições de Ensino Superior, uma vez que o processo de mudanças agora em andamento, não envolve estas instituições colaborativamente no debate das transformações. O atual CNE, coloca-se como representante de um setor da sociedade o setor empresarial - como instância decisória dos rumos da educação no país, deixando assim de "cumprir sua responsabilidade institucional de zelar pelo desenvolvimento plural e democrático da educação nacional” (FREITAS, 2021, s/p.).

Em 11/09/2020, por Portaria, foi criada neste Conselho uma Comissão Bicameral que apresentou recentemente (em fevereiro de 2021) uma proposta, que está em discussão, para alinhar o Curso de Pedagogia às determinações da Res. n. ${ }^{\circ}$ 2/2019, que normatiza agora a formação de professores. Tal proposta, que traz como título "Diretrizes 
Curriculares Nacionais de Pedagogia: Proposta Preliminar em Discussão", apresenta, entre outros detalhamentos, a discussão em andamento sobre os percursos curriculares específicos para a formação dos professores de Educação Infantil e Anos Iniciais do Ensino Fundamental, já determinados pela Res. n. ${ }^{\circ}$ 2/2019, propondo uma base comum e outra diversificada para as habilitações em Licenciatura Multidisciplinar em Educação Infantil; e Licenciatura Multidisciplinar em Ensino Fundamental. Coloca-se, portanto, uma preocupante ruptura com a concepção de formação integrada para a infância de 0 a 10 anos, consensuada nas discussões que precederam as DCNP de 2006, e que tiveram papel fundamental na definição da base docente para a formação integrada dos professores para a educação infantil e dos anos iniciais do ensino fundamental.

Outra questão que se coloca pela proposta, tem a ver com o conteúdo da gestão na escola, questão fundamental para a sua democratização, e que avançara na legislação anterior, agora contestada, no sentido de ser incluída na formação de todos os docentes. Retorna a proposição de formar no Curso de Pedagogia, especialistas para o trabalho escolar, por meio de habilitações diferenciadas que nitidamente propiciavam uma separação entre educadores "dirigentes" e aqueles "dirigidos” (FREITAS, 2021, s/p.).

Ao lado de tantos desafios, a escola pública, laica, democrática e de qualidade para todas as camadas da população brasileira exige de nós, educadores, não só a resistência às perdas dos avanços alcançados anteriormente, em períodos em que a participação dos educadores nas decisões normativas possuía efetivos espaços para as discussões e decisões, mas também a força e a luta de continuar estudando e propondo caminhos para uma qualidade referenciada nas necessidades formativas do processo de efetiva integração de todos e todas numa sociedade justa.

\section{Referências}

ANFOPE. Associação Nacional pela Formação dos Educadores. Documento Final IX Encontro Nacional. Campinas: ANFOPE, 1998.

ALBINO, Ângela Cristina Alves; SILVA, Andréia Ferreira da. BNCC e BNC da formação de professores: repensando a formação por competências. Retratos da Escola, v.13, n.25, 137-153,2019

BRZEZINSKI, Iria. Pedagogia e formação de professores: Dilemas e perspectivas. In Ensino e pesquisa em didática, metodologias e prática de ensino: Anais do VIII ENDIPE, Florianópolis, abril, 1996 (61-62). 
BRASIL. Decreto-Lei no 1.190, de 4 de abril de 1939. Organização da Faculdade Nacional de Filosofia. 1939.

BRASIL. Decreto no 3.276, de 6 de dezembro de 1999. Dispõe sobre a formação em nível superior de professores para atuar na educação básica e dá outras providências. Diário Oficial da União, Brasília, 7 dez. 1999.

BRASIL. Lei n. 9.394/1996, de 20 de dezembro de 1996. Lei de Diretrizes e Bases da Educação Nacional, Ministério da Educação. Brasília, 1996.

BRASIL. Conselho Nacional de Educação. Resolução CNE/CP n. ${ }^{\circ}$ 1/2002, de 18 de fevereiro de 2002a. Institui Diretrizes Curriculares Nacionais para a Formação de Professores da Educação Básica, em nível superior, cursos de licenciatura, de graduação plena. Diário Oficial da União, Brasília, 9 abr. 2002, Seção 1, p.31.

BRASIL. Conselho Nacional de Educação. Resolução CNE/CP n. ${ }^{\circ}$ 2/2002, de 19 de fevereiro de 2002b. Institui a duração e a carga horária dos cursos de licenciatura, de graduação plena, de formação de professores da Educação Básica em nível superior. Diário Oficial da União, Brasília, 4 mar. 2002, Seção 1, p.9.

BRASIL. Resolução n. ${ }^{\circ} 1$, de 15 de maio de 2006. Institui Diretrizes Curriculares Nacionais para o Curso de Graduação em Pedagogia, licenciatura. Diário Oficial da União, Seção 1, p.11. Conselho Nacional de Educação, Brasília, DF 16 mai, 2006.

BRASIL. Instituto Nacional de Estudos e Pesquisas Anísio Teixeira. Sinopse do Censo do Ensino Superior 2014. Brasília: INEP, 2014.

BRASIL. Parecer CNE/CP n. ${ }^{\circ}$ 2/2015, de 09 de junho de 2015. Diretrizes Curriculares Nacionais para a Formação Inicial e Continuada dos Profissionais do Magistério da Educação Básica, Ministério da Educação, Brasília, 2015a.

BRASIL. Resolução $n .^{o} 2$, de $1^{o}$ de julho de 2015. Define as Diretrizes Curriculares Nacionais para a formação inicial em nível superior (cursos de licenciatura, cursos de formação pedagógica para graduados e cursos de segunda licenciatura) e para a formação continuada. Ministério da Educação, Brasília, 2015.

BRASIL. Ministério da Educação. Base Nacional Comum Curricular: Educação é a base. Disponível em: <http://basenacionalcomum.mec.gov.br/>. Acesso em: 07 fev. 2017.

BRASIL. Resolução CNE/CP n. ${ }^{\circ}$ 2, de 20 de dezembro de 2019. Define as Diretrizes Curriculares Nacionais para a Formação Inicial de Professores para a Educação Básica e institui a Base Nacional Comum para a Formação Inicial de Professores da Educação Básica (BNC-Formação). Brasília, 2019.

BRASIL. Resolução CNE/CP n. ${ }^{\circ}$, de 27 de outubro de 2020. Dispõe sobre as Diretrizes Curriculares Nacionais para a Formação Continuada de Professores da Educação Básica e institui a Base Nacional Comum para a Formação Continuada de Professores da Educação Básica (BNC-Formação Continuada). Brasília, DF, 2020. 
CAMPOS, Roselane Fátima. O cenário da formação de professores no Brasil: Analisando os impactos da reforma da formação de professores. 2004. Texto cedido pela autora.

CHAGAS, Valnir. Formação do magistério: novo sistema. São Paulo: Atlas, 1976.

COUTINHO, Carlos Nelson. Gramsci: um estudo sobre seu pensamento político. Rio de Janeiro: Civilização Brasileira, 1999.

DALLABRIDA, N. A Reforma Francisco Campos e a modernização nacionalizada do ensino secundário. Revista Educação. Porto Alegre, volume 32, n.2, p. 185-191, 2009. Disponível em: http://revistaseletronicas.pucrs.br/ojs/index.php/faced/article/viewFile/5520/4015.

DURLI, Zenilde. O processo de construção das diretrizes curriculares nacionais para o curso de pedagogia: Concepções em disputa. Tese de Doutorado, Programa de Pósgraduação em Educação - Universidade Federal de Santa Catarina, Florianópolis, Brasil, 2007

DURLI, Zenilde; BAZZO, Vera Lúcia. Diretrizes Curriculares para o curso de pedagogia: Concepções em disputa. Atos de Pesquisa em Educação - PPGE/ME FURB. 3 (2), (201226), 2008.

FREITAS, Helena Costa Lopes. A reforma do ensino superior no campo da formação dos profissionais da educação básica: As políticas educacionais e o movimento dos educadores. Educação e Sociedade, 20 (68), 17-44, 1999.

FREITAS, Helena Costa Lopes. Formação inicial e continuada: A prioridade ainda postergada. In D. A. Oliveira \& L. F. Vieira. Trabalho na educação básica: A condição docente em sete estados brasileiros (91-130). Belo Horizonte: Fino Traço Editora, 2012.

FREITAS, Helena Costa Lopes. CNE indica os caminhos para a destruição da educação e da pedagogia. Formação de professores - Blog da Helena. Campinas - SP, publicado em 11 de fev. 2021.

MICELI, Sergio. Intelectuais à brasileira. São Paulo: Companhia das Letras, 2001.

QUARESMA, Maisa dos Reis. Expansão dos cursos de Pedagogia no Brasil. Comunicação científica: Anais do IV Seminário Nacional de Estudos e Pesquisas "História, Sociedade e Educação no Brasil". Campinas, 14-19 dez. 1997 (551-560), 1997

RAMOS, Mozart Neves. Novas diretrizes para a formação de professores. Qualidade do docente é o fator principal na educação. Folha de São Paulo, edição de 24 de novembro. São Paulo, 2019.

SAVIANI, Dermeval. O espaço acadêmico da pedagogia no Brasil: Perspectiva histórica. Paidéia - Cadernos de Psicologia e Educação, 14 (28), 113-124, 2004 
SAVIANI, Dermeval. Formação de professores: aspectos históricos e teóricos do problema no contexto brasileiro. Rev. Bras. Educ. [online]. 2009, vol.14, n.40, jan/abril, 142-155, 2009.

SAVIANI, Dermeval. Pedagogia histórico-crítica, quadragésimo ano: novas aproximações. Campinas: Autores Associados, 2019. 347 p.

SANTOS, Boaventura de Sousa. A cruel pedagogia do vírus. Coimbra: Edições Almedina, 2020.

SCHEIBE, Leda; AGUIAR, Márcia Angela. Formação de profissionais da educação no Brasil: O curso de pedagogia em questão. Educação e Sociedade, 20 (68), 220-238, 1999.

SCHEIBE, Leda; BAZZO, Vera Lúcia. A construção de uma base comum nacional para a formação de profissionais da educação no Brasil. Contrapontos, 1 (1), 91-103, 2001

SCHEIBE, Leda; DURLI, Zenilde. Curso de Pedagogia no Brasil: Olhando o passado, compreendendo o presente. Educação em Foco, 14 (17), 79-109, 2011.

SCHEIBE, Leda; BAZZO, Vera Lúcia. De volta para o futuro... retrocessos na atual política de formação docente. Retratos da Escola, v. 13, n. 27 , 669-684, 2019.

SILVA, Carmem Silvia Bissolli. Curso de pedagogia no Brasil: História e identidade. Campinas, SP: Autores Associados, 2003.

SILVA, Andréia Ferreira da. Formação de professores para a Educação Básica no Brasil: projetos em disputa (1987-2001). Niterói, 2004. 388 f. Tese (Doutorado em Educação) Faculdade de Educação, Universidade Federal Fluminense.

TANURI, Leonor Maria. História da formação de professores. Revista Brasileira de Educação, Rio de Janeiro, no 14, mai./jun./jul./ago., 2000.

\footnotetext{
* Leda Scheibe é Doutora em Educação pela Pontifícia Universidade Católica de São Paulo. Professora Titular Emérita, aposentada da Universidade Federal de Santa Catarina. Atualmente é Editora da Revista Retratos da Escola (Esforce/CNTE). Florianópolis, SCBrasil.

E-mail: lscheibe@uol.com.br

ORCID: https://orcid.org/0000-0002-5312-7633
} 
** Zenilde Durli é Doutora em Educação pela Universidade Federal de Santa Catarina. Professora Associada da Universidade Federal de Santa Catarina. Membro do Grupo de Pesquisa Itinera. Florianópolis, SC - Brasil.

E-mail: zenilde.durli@ufsc.br

ORCID: https://orcid.org/0000-0001-8629-7658. 